\title{
UMA EXPERIÊNCIA DE ENSINO DA LÍNGUA ITALIANA ESCRITA NA Universidade de São Paulo
}

Cecilia Casini

RESUMO: A partir de um projeto de pesquisa sobre a didática do italiano no Brasil, apresenta-se a experiência de dois anos de ensino da língua italiana escrita, realizada nos cursos de graduação em Letras da Universidade de São Paulo. Neste período, a autora trabalhou a língua italiana escrita com turmas de diferentes níveis, procurando transferir para a prática da sala de aula os princípios teóricos da didática relacionada ao assunto.

PALAVRAS-CHAVE: didática; língua italiana; língua portuguesa; oralidade; escritura.

ABSTRACT: Partendo da un progetto di ricerca sulla didattica dell'italiano in Brasile, si presenta l'esperienza di due anni di insegnamento della lingua italiana scritta, realizzata nei corsi di laurea in Lettere dell'Università di San Paolo. In questo periodo, l'autore ha lavorato con la lingua italiana scritta con due classi di livelli diversi, cercando di applicare in classe i principi teorici della didattica su questo argomento.

PAROLE CHIAVE: didattica; lingua italiana; lingua portoghese; oralità; scrittura. 
ABSTRACT: As a result of a research project on the didactics of Italian language in Brazil, I hereby present my two-year experience as professor of written language in São Paulo University. In this period, I worked on written Italian language with students of different levels, trying to apply the theoretical principles of didactics to the everyday reality of the classroom.

KEYWORDS: didactics; Italian language; Portuguese language; spoken language; written language. 


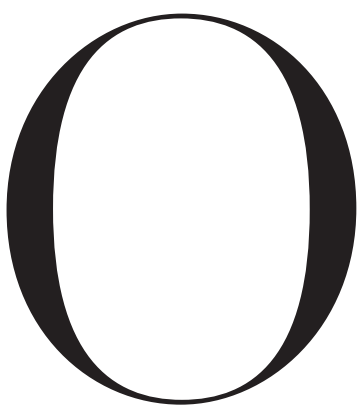

presente artigo tem como objetivo apresentar uma experiência realizada com estudantes de cursos de graduação em italiano da USP, para o ensino da língua escrita, em 2007 e 2008. No decorrer deste período, procurou-se aplicar, na prática didática da sala de aula, algumas propostas incluídas em um projeto institucional ${ }^{1}$ sobre a didática da língua italiana escrita. ${ }^{2}$

\section{Atividades na sala de aula: primeiro e segundo semestre de 2007}

No primeiro e no segundo semestre de 2007 o curso foi ministrado para duas turmas: Língua Italiana I (alunos iniciantes absolutos de italiano) e Língua Italiana III (alunos com um conhecimento intermediário de língua italiana, tendo já frequentado dois semestres completos de curso). O programa específico de língua escrita foi estruturado da seguinte maneira:

- características da oralidade (primeiro semestre, turmas Italiano I e Italiano III);

- do texto oral ao texto escrito (primeiro semestre, turmas Italiano I e Italiano III);

- características da escrita (segundo semestre, turmas Italiano II e Italiano IV);

- as diferentes modalidades textuais na escrita (segundo semestre, turmas Italiano II e Italiano IV).

\footnotetext{
1. Objeto do artigo "Didática da língua escrita: um projeto de ensino e pesquisa na área de italianistica”. Revista de Italianistica, n.XIII, 2006. 2. A experiência de ensino da língua italiana, precedente ao ingresso na universidade, tinha proporcionado à autora contato com a língua, em todas suas modalidades, sendo ocasião de estudos e reflexões de vários tipos. No entanto, atividades específicas concernentes à língua escrita acabavam sempre sendo consideradas em último plano, devido ao escasso tempo à disposição nos cursos livres e à dificuldade de planejamento dos mesmos. Essa situação acabava gerando um impasse, pois justamente a falta de tempo e, sobretudo, de continuidade prejudicava a aplicação, na sala de aula, das orientações teóricas a respeito do assunto em questão. Impasse que, naquelas condições, não era possível contornar. Para superar esta situação, foi elaborado um projeto de pesquisa focalizado na didática da língua italiana escrita; projeto que, pela peculiaridade das condições de trabalho proporcionadas pela instituição universitária, teria seu núcleo ideal dentro dela própria.
} 
Com efeito, entendeu-se ser importante, antes de enfrentar mais especificamente o texto escrito, oferecer aos discentes a possibilidade de refletir sobre "as mudanças nos próprios modos do pensamento e da percepção, mudanças que se trasmitem por meio de uma organização mental e do discurso independente dos conteúdos explícitos e, portanto, da consciência dos indivíduos na qual se gravam”3 (ONG, 1986, p. 8), mudanças que acompanham as transformações da palavra da fase oral para a fase escrita. Assim, os discentes poderiam adquirir consciência das diferenças entre as duas modalidades de produção da palavra: a oral, que tem dificuldade de separar o objeto do sujeito da percepção, e a escrita, que realiza essa distinção (ONG, 1986, p. 9). Uma reflexão mais profunda a respeito dos processos de interiorização da palavra falada proporciona uma melhor abordagem dos mecanismos de suas transformações tecnológicas (ONG, 1986, 122), no caso, a passagem para a palavra escrita. Quando se aborda a escrita, tem que se ter consciência de que esta é "um processo dirigido por normas conscientemente inventadas e claramente formuláveis" ${ }^{4}$ (ONG, 1986, p. 123); ou seja, tem que se saber que o discurso escrito baseia-se em convenções que é preciso conhecer. É importante que os discentes entendam o valor essencial da escrita para o pleno desenvolvimento da interioridade humana, pois ela pressupõe "transformações das estruturas humanas [...] positivas"5 (ONG, 1986, p.124), entre as quais está o maior grau de autoconsciência de quem se expressa por escrito, devido ao necessário distanciamento da palavra escrita de seu objeto.

É preciso também acreditar que a escrita, a mais difícil entre as habilidades linguísticas para quem estuda um idioma, pode ser concretamente ensinada e, portanto, aprendida, mesmo que com algumas limitações. Um procedimento indispensável é levar o discente ao conhecimento do processo de construção do texto escrito, mediante sua descontrução, operação que permite dominá-lo. Segundo Beltramo, é oportuno identificar as fases e descrevê-las detalhadamente, para conseguir-se, assim, redimensionar o poder intimidador da escrita para quem se prepara a enfrentá-la, especialmente se não é nativo: "A escrita torna-se uma técnica e, como tal, pode ser ensinada” (BELTRAMO, 2000, p. 27).

Essas considerações marcaram, na Itália, uma mudança na tradição do ensino da língua escrita, que, até pouco tempo, era considerada uma habilidade que só se podia aprender com base no princípio da imitação, a ser cultivada com muitas leituras. A partir de 1999, outras provas, "diferentes [não] somente na formulação e no assunto proposto, mas também na modalidade de redação do texto", ${ }^{7}$ como o artigo de jornal, a redação, o ensaio, "mais objetivas e transparentes"8 (DE DOMINICIS, 2008, p. 7), se juntaram à redação em italiano, prova capital do "Esame di maturità", exame conclusivo do curso secundário superior.

Um texto escrito deve ser eficaz, para alcançar verdadeiramente seu objetivo comunicativo; portanto, tem que ser "pensado e construído segundo regras especiais definidas

3. "i mutamenti nei modi stessi del pensiero e della percezione, mutamenti che si trasmettono attraverso un'organizzazione mentale e del discorso indipendente dai contenuti espliciti e dunque dalla consapevolezza degli individui su cui si imprimono" (tradução nossa).

4. "un processo guidato da norme consapevolmente inventate, e chiaramente formulabili" (tradução nossa).

5. "trasformazioni delle strutture umane [...] positive" (tradução nossa).

6. "La scrittura diventa una tecnica e, come tale, diventa insegnabile" (tradução nossa).

7. “diverse [non] solo nella formulazione e nell'argomento da trattare suggerito, bensì anche nelle modalità di stesura del testo" (tradução nossa).

8. "più oggettive e trasparenti" (tradução nossa).

9. "pensato e costruito secondo regole particolari dettate dallo scopo della comunicazione, dal tipo di destinatario e dall'oggetto del discorso" (tradução nossa). 
pelo objetivo da comunicação, pelo tipo de destinatário e pelo objeto do discurso ${ }^{9}$ (BELTRAMO, 2000, p. 28). Contudo, na prática da sala de aula, tentou-se sempre, dependendo do tipo de texto, juntar a perspectiva pragmática, que privilegia o texto come instrumento de comunicação, à literária, que enfatiza os aspectos estilísticos do discurso.

Com ambos os grupos, começou-se a trabalhar mais especificamente a língua escrita depois de dois meses de aula. Na primeira abordagem, a reflexão linguística procurou evidenciar a profunda diferença entre o uso oral e o uso escrito de uma língua; como a língua escrita tem que abstrair da fisicidade do indivíduo que fala, na medida em que precisa tornar "idealmente presentes dois interlocutores distantes entre si"10 (BRUNI-RASO, 2002, p. 4); quais são os recursos particulares que a escrita usa para "resgatar a ruptura da distância"ll (BRUNI-RASO, 2002, p. 4); se e como é possível reproduzir a língua falada em língua escrita (por exemplo, nos diálogos e nas falas de textos narrativos e teatrais). Enfim, é preciso que os discentes se deem plenamente conta da específica função "transacional”, ou seja, de troca de informações, da língua escrita, com relação à função "interacional”, de negociação de relações, da língua falada (BRUNI-RASO, 2002, p. 4), antes de começar a enfrentar a redação de textos escritos.

Portanto, analisou-se a organização da comunicação na língua escrita: como mudam as categorias do espaço e do tempo (em particular, como a dimensão temporal se dilata); como a ausência do feedback repercute na língua escrita; como o nível de tolerância com relação aos descuidos expressivos (“trascuratezze espressive”, BRUNI-RASO, 2002, p.7) difere (o que torna obrigatória uma cuidadosa projetação do texto escrito); como a carga de informações da língua escrita requer uma sintaxe mais esmerada, com pleno controle sobre as estruturas da subordinação do discurso (o que se traduz em uma necessidade maior de conhecimento da morfologia das formas verbais; das relações entre os tempos verbais; do uso dos conetivos; do uso da anáfora e da catáfora; das formas e do uso dos pronomes, etc.); como a tematização, tão comum na oralidade, passa a funcionar nos textos escritos; como o léxico pode ser usado de maneira diferente; como a função da pontuação, visando dar maior legibilidade ao texto escrito, se torna lógico-sintática, etc.

Foram apresentados os diferentes tipos textuais, classificados como injuntivos, informativos, descritivos, narrativos e argumentativos (conforme BRUNI-ALFIERI-FORNASIERO-TAMIOZZO GOLDMANN, 2006, p. 37-83). Tratou-se o texto como a unidade fundamental da língua, como "o conjunto de frases e conectivos frasais, que são os elementos que garantem a ligação entre as partes"12 do discurso (BRUNI-RASO, 2002, p. 38). Com a colaboração dos próprios alunos, estimulados desde o começo a tomar parte da discussão - pois as habilidades cognitivas que estão na base da aquisição linguística são consideradas universais, pelo menos nas línguas ocidentais (BELTRAMO, 2000, p. 13) -, procurouse logo apresentar as características de cada tipo textual; ao mesmo tempo, chamava-se

10. “idealmente presenti due interlocutori lontani tra loro" (tradução nossa).

11. "risarcire lo strappo della distanza" (tradução nossa).

12. "l'insieme di frasi e connettori frasali, che sono gli elementi che assicurano il collegamento tra le parti" (tradução nossa). 
a atenção para o fato de que, muitas vezes, existem textos mistos, nos quais é necessário individuar a forma discursiva dominante. Nessa fase, foram apresentados textos em que era preciso indicar as partes referentes a cada tipo textual, de maneira a acostumar os discentes a refletir, antes de passar a praticar a língua escrita, sobre as peculiaridades dos textos reais (autênticos) e a orientá-los para distingui-las entre si.

Embora se considere extremamente importante a reflexão teórica acerca deste tema, achou-se necessário, no caso específico da língua escrita, passar rapidamente à produção de textos por parte dos discentes, pois pode ser frustrante para os alunos tratarem de um tema tão rico e complexo de um ponto de vista teórico, sem ter acesso à prática imediata da escritura. Portanto, isso ocorreu já no começo, contemporaneamente à fase da abordagem teórica. Os exercícios propostos aos alunos, devido à diferença de nível entre as turmas, eram de diferente complexidade (em termos de tempo e de tamanho), diferiam nas tipologias textuais e eram graduados conforme a "modalità attuattiva" (DELLA CASA, 1994, p. 132-133), ou seja, de acordo com os "valores de uma série de parâmetros que determinam o grau de dificuldade de uma tarefa de escrita"13 (BELTRAMO, 2000, p.14), de cada um deles.

As aulas destinadas à escritura eram planejadas da seguinte forma: primeiramente, fornecia-se aos alunos material, de autoria do docente ou selecionado de livros, como introdução teórica, que os alunos liam juntos na sala de aula, discutiam e comentavam e, posteriormente, reliam em casa, procurando aprofundar a compreensão. O objetivo era que os alunos se familiarizassem o mais possível com o assunto do ponto de vista teórico, tomando consciência das diferenças entre os dois canais de comunicação: o oral e o escrito.

Depois de ter estudado a especificidade do canal oral e as diferenças entre a língua falada e a língua escrita e de ter visto como se dá a passagem de um canal para outro, entrava-se no vivo da reflexão sobre a escrita, analisando mais de perto suas características, como também as várias modalidades textuais. Perguntas teóricas sobre assuntos vistos previamente entraram nas provas escritas aplicadas ao longo do semestre. As atividades práticas realizadas foram as seguintes:

- Trabalhos de reformulação de textos destinados a serem ouvidos (ou seja, textos falados) em textos destinados a serem lidos (ou seja, textos escritos). Este tipo de exercício ativa uma das habilidades mais importantes da escrita, que é "a capacidade de isolar um conteúdo informativo e de reformulá-lo"14 (BRUNI-RASO, 2002, p. 201), que permite que os alunos adquiram "uma consciência profunda das diferenças entre o escrito e o falado"15 (BRUNI-

13. "valori di una serie di parametri che determinano il grado di difficoltà di un compito di scrittura" (tradução nossa).

14. "la capacità di isolare un contenuto informativo e riformularlo daccapo" (tradução nossa).

15. "una consapevolezza profonda delle differenze tra lo scritto e il parlato" (tradução nossa). 
RASO, 2002, p. 202), tomando consciência dos precípuos mecanismos da oralidade, com relação aos da escrita. Trata-se de exercícios importantes para uma primeira abordagem do tema, especialmente úteis para desenvolver a capacidade de isolar o conteúdo informativo de um texto e de reformulá-lo na base de novas informações. Para tanto, foram escolhidos textos de canções e transcrições de trechos de programas radiofônicos.

- Listas dos fenômenos das mudanças linguísticas mais frequentes neste tipo de reformulação (por exemplo, os elementos da dêixis; os sinais discursivos; a passagem do discurso direto para o discurso indireto; a coordenação e a subordinação entre as frases; os tempos verbais). Realizar esses elencos serviu para que os alunos tivessem à disposição um pequeno guia, prático e ágil, feito por eles mesmos, como primeiro ‘dicionário pronto’ específico para a escrita: não um instrumento de trabalho a ser usado mecanicamente, mas local da sistematização dos conhecimentos adquiridos até aquele momento.

- Respostas simples às perguntas sobre os livros escolhidos como textos de leitura obrigatória. É praxe dos cursos de língua italiana escolher um livro por semestre, para ser lido integralmente em língua original. Com base neles (os livros foram dois, um para cada curso), foram realizados dois questionários diferentes, com perguntas relativas ao conteúdo e a outros aspectos dos livros. Os alunos tiveram que responder por escrito, preferivelmente em italiano (Língua Italiana I e II), ou obrigatoriamente em italiano (Língua Italiana III e IV). O que foi julgado na avaliação final, valendo nota, não foi a perfeição do texto em italiano - coisa bem difícil de exigir, visto o pouco tempo de estudo dos alunos até então -, mas a efetiva leitura do livro, junto com a fluidez da expressão verbal do texto. $\mathrm{O}$ fato de a perfeição da língua nas respostas não pesar na nota fez com que os alunos se sentissem à vontade para escrever, às vezes alternando respostas mais simples em italiano com respostas mais complexas em português, superando a timidez para com a prática escrita da língua.

- Pequenos comentários, em forma de reflexão pessoal, como respostas a algumas perguntas, relativas à língua italiana, que poderiam aparecer na prova final. Foi uma tentativa, baseada na consideração da aquisição natural da língua, de aproximar os alunos do texto argumentativo, já nas primeiras fases do estudo da língua italiana escrita. Nesse caso, as respostas eram fa- 
cultativas e sem nota; mesmo assim, a maioria dos alunos optava por responder, produzindo, às vezes, textos bastante interessantes.

\section{Atividades na sala de aula: primeiro e segundo semestre de 2008}

Em 2008, o grupo de Língua Italiana III e IV, que agora passara para Língua Italiana V e VI, continuou o curso de língua escrita. Conforme a grade curricular, para esses níveis de ensino linguístico são previstas duas horas de produção de textos (ou seja, de atividades escritas) por semana. Portanto, é possível trabalhar, com um pouco mais de tempo e de atenção, a prática da escrita.

Para os dois semestres, foi seguido o cronograma abaixo:

- primeiro semestre (turma Italiano V): o texto informativo, descritivo e narrativo;

- segundo semestre (turma Italiano VI): o texto argumentativo.

Retomando o conteúdo do semestre anterior, em que se tinha falado da língua escrita em suas possíveis modalidade textuais, começou-se agora a analisar mais de perto a informação, a descrição e a narração, para, em seguida (no segundo semestre), enfrentar o tipo de texto mais difícil, o argumentativo.

O planejamento das aulas continuou nos moldes dos dois semestres anteriores: começava-se por uma introdução teórica (baseada em textos fornecidos pelo docente), para propiciar a reflexão sobre as características mais marcantes dos vários tipos textuais, do ponto de vista lexical e sintático. Em seguida, passava-se a praticar a escrita, conforme as diferentes tipologias textuais abordadas. Muito importante foi a fase do planejamento do texto, ou seja, o momento da pré-escritura, "a primeira macroatividade do processo de construção do texto [que] leva à realização de um roteiro mais ou menos explícito"16 (BELTRAMO, 2000, p. 28). A esta segue-se a fase da redação do texto; e finalmente, importantíssima, a fase da revisão do texto. Foram realizadas tarefas escritas com graus progressivos de dificuldade, até chegar a redações mais complexas, nos vários tipos textuais.

Quanto à produção, os alunos foram estimulados a escrever:

16. "la prima macro-attività del processo di costruzione del testo [che] conduce alla realizzazione di una più o meno esplicita scaletta" (tradução nossa). 
- Redações de textos de tipo informativo, descritivo e narrativo, tais como: descrições em forma de apresentação (de si mesmo e de outras pessoas; de lugares variados; de eventos); resumos (com mudanças ou não de recorte); cartões postais e pequenas cartas; notícias e/ou crônicas de jornais. Estas operações serviam para desenvolver a capacidade dos discentes de representar com elementos linguísticos pessoas, objetos, eventos, indicando suas características; de selecionar e hierarquizar as informações de um texto, de várias maneiras conforme diversos pontos de vista ou em relação a públicos diferentes; de distinguir o recorte de um texto das informações que ele contém. O resumo, por exemplo, é uma atividade para cuja realização quem escreve "não precisa adquirir novas informações, mas simplesmente escolher e adaptar à nova orientação as disponíveis na fonte"17 (BRUNI-RASO, 2002, p. 210). Trata-se, portanto, de um exercício que ensina a "distinguir o recorte textual com seu objetivo comunicacional das informaações que ele contém"18 (BRUNI-RASO, 2002, p. 210) e, em última análise, a ler criticamente as fontes (BRUNI-RASO, 2002, p. 210).

- Redações de textos de tipo argumentativo, sem documentação e exemplificação, com ou sem vínculos, tais quais: ensaios acerca de textos famosos da literatura brasileira, com o intuito de apresentá-los para o público italiano; resenhas de filmes italianos (que tinham sido vistos previamente), para apresentação ao público brasileiro; dois diferentes artigos jornalísticos, realizados pelos alunos divididos em dois grupos competindo entre si; um ensaio em forma de crítica literária, acerca de um texto em que foi baseado o exame oral do curso (portanto, conhecido por todos os alunos). De um ponto de vista didático, as atividades concernentes à argumentação são especialmente úteis para a correta utilização dos conetivos, utilizados para estabelecer as relações entre as várias partes do discurso. As atividades concernentes à argumentação visam distingui-la da documentação e da exemplificação; quem desenvolve uma argumentação deve ser capaz de fornecer razões para afirmar uma tese, ou seja, "deve dizer por que a tese é válida, recorrendo a um raciocínio"19 (BRUNI-RASO, 2002, p. 287). Trabalhando com a argumentação, os discentes aprendem a se relacionar com o outro, pois não podem prescindir da situação comunicativa em que a argumentação acontece, tendo que sustentá-la com base em argumentos diferentes, dependendo do tipo de destinatário. No caso da argumentação, de fato, “estamos no âmbito da

17, "non deve acquisire nuove informazioni ma semplicemente scegliere e adattare al nuovo orientamento quelle disponibili nella fonte" (tradução nossa). 18. "a distinguere il taglio testuale con il suo scopo comunicativo dalle informazioni che esso racchiude" (tradução nosssa). 19. “deve dire perché la tesi è valida, appellandosi a un ragionamento” (tradução nossa). 
opinião” e “a capacidade de persuadir um destinatário fundamenta-se [...] no compartilhamento da visão de mundo sobre o qual se apoiam os argumentos"20 (BRUNI-RASO, 2002, p. 288).

- Listas de elementos e de estruturas linguísticas, recorrentes em textos de tipo descritivo, narrativo e argumentativo, como: adjetivos (em textos basicamente descritivos); tempos verbais (alternância do imperfeito com o passado, em textos basicamente narrativos; o presente e as várias formas do passado, em textos basicamente argumentativos; etc.); indicadores de tempo e de espaço (em textos basicamente narrativos e descritivos); a transformação dos sinais discursivos e vários outros tipos de indicadores (de acordo/desacordo; de certeza/incerteza; de avaliação; de focalização; de verdade/falsidade; introdutores/modificadores de afirmações; indicadores meta-argumentativos; quantificadores, etc., em textos basicamente argumentativos).

- Respostas às perguntas sobre os livros escolhidos como textos de leitura obrigatória, conforme ocorreu nos dois semestres de 2007. Dessa vez, as perguntas eram mais elaboradas, requerendo nas respostas um grau mais elevado de cuidado formal e uma maior complexidade lexical e sintática.

- Comentários, em forma de reflexão pessoal, como resposta a perguntas contidas na prova escrita. Dessa vez, com relação ao experimento equivalente nos dois semestres de 2007, tratou-se de respostas obrigatórias a perguntas mais complexas sobre a língua italiana, valendo nota.

Momento conclusivo dos trabalhos era sempre o da revisão e da correção. Foram realizados tipos diferentes de correção: um, relativo aos vários trabalhos que os alunos realizavam ao longo do período das aulas, nem sempre obrigatórios, e que deviam ser entregues ao docente para avaliação; neste caso, o docente analisava cada trabalho, em casa ou na sala de aula, e assinalava por escrito os erros, as imprecisões ou o que podia haver de notável no texto. Em seguida, os trabalhos corrigidos eram devolvidos aos alunos, que tinham plena liberdade para pedir esclarecimentos adicionais, em caso de dúvidas. Outro, relativo principalmente às provas - iguais para todos os estudantes -- aplicadas durante o semestre: neste caso, o docente corrigia os trabalhos em casa, simplesmente assinalando os erros; posteriormente, na sala de aula, ao devolver as provas corrigidas aos alunos, o docente pedia que eles mesmos tentassem uma primeira correção, feita em comum e diante de todos, exercício por exercício. 
Pelo que diz respeito à prática da escrita mais discursiva, como os resumos, as narrações, os textos argumentativos produzidos pelos estudantes especialmente nos dois semestres de 2008, fazia-se a correção de todos os trabalhos, da mesma maneira que para as atividades acima citadas; mas também selecionavam-se alguns textos, julgados especialmente interessantes, para servir de objeto de uma correção, ou melhor, de uma análise mais pontual e detalhada. A revisão que visa desmontar criticamente um texto é um momento muito importante da 'tomada de consciência' linguística de quem escreveu aquele texto, pois é a partir dela que se pode ver como aconteceu o processo inverso, o processo da montagem: a desmontagem "obriga a fazer uma análise concreta, porque põe à prova as regras que interiorizamos”21 (BELTRAMO, 2000, p. 31). Para tanto, o docente digitava o texto escolhido no computador sem alterálo absolutamente, ou seja, reproduzindo-o exatamente como tinha sido escrito pelo aluno; depois, ampliava o tamanho da letra e o imprimia em uma folha transparente. $\mathrm{Na}$ sala de aula, o texto era projetado e analisado detalhadamente em conjunto pelo docente e pelos discentes, que eram chamados a participar ativamente com sugestões, ideias, observações. O docente deixava que a maior parte possível do texto fosse corrigido ou comentado pelos próprios estudantes. Primeiro, o docente orientava os alunos a comentar o texto do ponto de vista linguístico, sinalizando as falhas morfológicas, gramaticais e sintáticas; depois, passava aos comentários de tipo estilístico-textual. À medida que as correções eram feitas, o docente as transcrevia com um pincel em cima da folha transparente, de maneira que todos os presentes pudessem acompanhar o trabalho de 'transformação' do texto, assim colaborando diretamente com o docente no esforço de melhorá-lo. Este trabalho foi especialmente proveitoso para os estudantes, que, aos poucos, foram vencendo a timidez e participando livremente e com desenvoltura da atividade proposta.

Em geral, as atividades escritas propostas entendiam verificar se os alunos

- possuíam um razoável domínio da língua italiana;

- tinham capacidade de escrever de maneira gramaticalmente e lexicalmente correta;

- conheciam os temas tratados (dependendo do tipo de texto);

- eram capazes de organizar um texto;

- eram capazes de elaborar e argumentar suas opiniões;

- eram capazes de desenvolver raciocínios consequentes e motivados;

- eram capazes de emitir julgamentos críticos e pessoais. 


\section{Considerações finais}

Todas as atividades realizadas com os alunos foram muito proveitosas, pois possibilitaram a coleta de material - principalmente, os trabalhos dos próprios estudantes - que, conforme o projeto de pesquisa citado no começo deste artigo, poderá servir de base para a elaboração de um método específico de ensino da língua italiana escrita, voltado para falantes de português brasileiro. 
ITALIANO COMO LÍNGUA ESTRANGEIRA | UMA EXPERIÊNCIA DE ENSINO DA LÍNGUA ITALIANA ESCRITA ! 53

\section{Bibliografia}

BELTRAMO, M. Abilità di scrittura. Torino: Paravia, 2000.

BRUNI, F.; ALFIERI, G.; FORNASIERO, S.; TAMIOZZO GOLDMANN, S. Manuale di scrittura e comunicazione.

2. ed. Bologna: Zanichelli, 2006.

BRUNI, F.; RASO, T. (Org.). Manuale dell'italiano professionale. Bologna: Zanichelli, 2002.

CAPELLA, P. Guida alla composizione di un testo scritto. Milano: Bignami, 2007.

DE DOMINICIS, B. La nuova prova scritta d'italiano. Napoli: Il Girasole, 2008.

DELLA CASA, M. Scrivere testi: il processo, i problemi educativi, le tecniche. Florença: La Nuova Italia, 1994.

FRUTTERO \& LUCENTINI. I ferri del mestiere: manuale involontario di scrittura con esercizi svolti. Torino:

Einaudi, 2003.

FULGÊNCIO, L.; BASTIANETTO, P. In Italiano: manuale di grammatica contrastiva. Perugia: Guerra, 1993.

MACHADO, A.R.; LOUSADA, E.; SANTOS ABREU TARDELLI, L. Planejar gêneros acadêmicos. São Paulo: Parábola Editorial, 2005.

ONG, W. Oralità e scrittura. Torino: Il Mulino, 1984.

PERELMAN, C.; OLBRECTS TYECA, L. Trattato dell'argomentazione. Torino: Einaudi, 2005.

SERIANNI, L.; TRIFONE, P. Scritto e parlato. Torino: Einaudi, 1994.

. (Org.). Storia della lingua italiana. II. Scritto e parlato. Torino: Einaudi, 1994.

TAMIOZZO GOLDMANN, S.; FORNASIERO, S. Scrivere l'italiano: galateo della comunicazione scritta. Bologna: Il Mulino, 1994. 